\title{
Do predators keep prey healthy or make them sicker? A meta-analysis
}

\author{
Robert Richards ${ }^{1}$, John Drake ${ }^{1}$, and Vanessa Ezenwa ${ }^{1}$ \\ ${ }^{1}$ University of Georgia
}

July 2, 2021

\begin{abstract}
Ecological theory suggests that predators should keep prey populations healthy by reducing parasite burdens. However, empirical studies show that predators often have minimal effects on, or even increase, parasitism in prey. To quantify the overall magnitude and direction of the effect of predation on parasitism in prey, we conducted a meta-analysis of 50 empirical studies. We also examined how key attributes of these studies, including parasite type, study design, and predator interaction type (consumptive vs. non-consumptive) contributed to variation in the predator-prey-parasite interaction. We found that the overall effect of predation on parasitism differed between parasites and parasitoids and that predator interaction type, and whether a predator was a non-host spreader of parasites were the most important traits predicting the parasite response. Our results suggest that the mechanistic basis of predator-prey interactions strongly influences the effects of predators on parasites and that these effects, while context dependent, are predictable.
\end{abstract}

Title: Do predators keep prey healthy or make them sicker? A meta-analysis

Short Title: Testing the healthy herds hypothesis

Article Type: Letter

Authors: Robert L. Richards ${ }^{1,2 *}$, John M. Drake ${ }^{1,2}$, Vanessa O. Ezenwa ${ }^{1,2,3}$

${ }^{1}$ Odum School of Ecology, University of Georgia, 140 E. Green Street, Athens, GA, 30602

${ }^{2}$ Center for the Ecology of Infectious Diseases, University of Georgia, 203 D. W. Brooks Drive, Athens, GA, 30602

${ }^{3}$ Department of Infectious Diseases, College of Veterinary Medicine, University of Georgia, 501 D.W. Brooks Drive, Athens, GA, 30602

* Corresponding author: Odum School of Ecology, 140 E. Green Street, Athens, GA, 30602; Phone: 617312-4802; e-mail:

robbielrichards@gmail.com

Keywords: predator, parasite, disease ecology, healthy herds hypothesis, meta-analysis, trophic interaction

Statement of authorship: RLR, JMD, and VOE conceived of the study. RLR performed literature search, collected and analyzed data, and wrote the first draft of publication. All authors contributed substantially to revisions.

Data accessibility statement: Data and code used in these analyses will be published on figshare upon acceptance of the manuscript and a do will be included in the article. Prior to acceptance data and code can be accessed at this private figshare link:https://figshare.com/s/ae13262817c42e4e82d9 
Abstract: 149 Words

Main Text: 4314 Words

Number of figures: 3

Number of Tables: 3

Number of References: 53

\section{ABSTRACT}

Ecological theory suggests that predators should keep prey populations healthy by reducing parasite burdens. However, empirical studies show that predators often have minimal effects on, or even increase, parasitism in prey. To quantify the overall magnitude and direction of the effect of predation on parasitism in prey, we conducted a meta-analysis of 48 empirical studies. We also examined how key attributes of these studies, including parasite type, study design, and predator interaction type (consumptive vs. non-consumptive) contributed to variation in the predator-prey-parasite interaction. We found that the overall effect of predation on parasitism differed between parasites and parasitoids and that predator interaction type, and whether a predator was a non-host spreader of parasites were the most important traits predicting the parasite response. Our results suggest that the mechanistic basis of predator-prey interactions strongly influences the effects of predators on parasites and that these effects, while context dependent, are predictable.

\section{INTRODUCTION}

Organisms navigate a complex set of interspecific interactions, among the most important of these being victimization by natural enemies. Both predators (Krebset al. 1995, 2018) and parasites (Hudson et al.1992b; Tompkins \& Begon 1999) can affect the population demography and dynamics of the species they attack. However, few organisms are victim to only a single natural enemy. Competition between predators of a single prey population (Holt \& Lawton 1994; Holt \& Polis 1997; Tallian et al. 2017) and between parasites within a single host organism (Pedersen \& Fenton 2007; Jolles et al. 2008; Ezenwa \& Jolles 2011) have both been studied for the effects that these interactions have on natural enemy and victim populations. But predators and parasites of a single victim population also interact in a variety of potentially important ways. Parasites may weaken their hosts, making them easier to catch and consume (Hudsonet al. 1992a; Moore 2002), while the killing and consuming of prey by predators also kills parasites (Hatcher et al.2006; Borer et al. 2007), except when the predator itself becomes the next host (Lafferty 1999; Kuris 2003; Logiudice 2003). Therefore, like other natural enemy interactions, interactions between predators and parasites are important to understanding the dynamics of natural populations.

Ecologists have long recognized the importance of predator-prey-parasite interactions (Hudsonet al. 1992a). Among the most influential hypotheses about the consequences of predator-prey-parasite interactions is Packer et al.(2003)'s prediction, based on a mathematical model, that predators reduce parasitism in their prey. This Healthy Herds Hypothesis (HHH) phenomenon might be produced by multiple mechanisms. First, predators directly, and often preferentially, kill infected individuals, decreasing the number of infected individuals in the population. Second, predators often reduce prey population sizes, which can decrease the spread of parasites with density dependent transmission. Empirical studies have tested the underlying predictions of the HHH in a variety of systems, but results are conflicting. Some studies show a strong negative effect of predators on parasites, while others show strong positive effects. For example, experimentally increased bird predation on lizard hatchlings (Acanthodactylus beershebensis ) decreased parasitic trombiculid mite loads in the lizards (Hawlena et al.2010), while sunfish (Lepomis gibbosus ) predators introduced into tanks with infected tadpoles (Lithobates spp. ), increased trematode cercarial load in tadpole prey (Szuroczki \& Richardson 2012). Interestingly, these empirical studies differ along multiple axes, including the transmission traits of the parasite (Holt \& Roy 2007; Roy \& Holt 2008) and the type of predator or predatory interaction manipulated (Cácereset al. 2009; Strauss et al. 2016; Duffy et al.2019) which may help explain the variation in outcomes. While early syntheses of the literature on predator-prey-parasite interactions argued 
for the importance of predators in disease ecology and human health (Ostfeld and Holt 2004) and contextualized these interactions within the broader landscape of ecological interactions (Hatcheret al. 2006), more recently, Duffy et al. (2019) laid out a framework of eight different types of mechanisms by which predators may influence parasitism in prey, all of which can result in either increases or decreases in parasitism under different circumstances. We draw on this framework, along with additional theoretical and empirical work to establish hypotheses about the effect of parasite and interaction type on predator-prey-parasite interactions.

We conducted a meta-analysis to quantify the overall magnitude and direction of the effect of predation on parasitism, providing a synthesis of the empirical work on this topic. We also tested the prediction that differences among studies explain variation in observed parasite responses along two key axes: (i) parasite type, and (ii) type of predatory interaction. Specifically, we predicted that effects of predators on macroparasites and parasitoids would be more negative than effects on microparasites, because macroparasites and parasitoids tend to be highly aggregated among hosts and spatial locations (Hassell 1982; Chesson \& Murdoch 1986; Shaw \& Dobson 1995) allowing small amounts of selective predation to nearly eliminate parasite populations. Parasitoids in particular have free-living adult stages which may fall prey to or avoid predators of their hosts (Heimpel et al.1997; Brodeur \& Rosenheim 2000). In this way, predation should necessarily affect parasitoids via a wider range of mechanisms than other parasites, including selective predation, shifts in community structure, and behavioral effects on the parasitoids themselves (Duffyet al. 2019). We also predicted that consumptive predatory interactions would have more negative effects on parasites than non-consumptive interactions, except when consumptive effects facilitate parasite spread. In this case, consumptive interactions should actually increase parasitism. The HHH predicts that, on average, consumptive interactions decrease parasitism because infected individuals are removed from populations (Packer et al.2003). However, this average effect of consumption on parasites should not apply in all circumstances and, in fact, more recent work suggests that all consumptive mechanisms can potentially increase parasitism under the right circumstances. (Duffy et al.2019). In particular, "predator-spreaders," which, although they cannot become infected, may facilitate the spread of parasites from their prey items by dispersing infectious agents more widely (Cáceres et al.2009). On the other hand, non-consumptive interactions can alter prey movement and space use behavior (Brown et al.1988; Spieler 2003; Jones \& Dornhaus 2011; Creel et al. 2014) in ways that predictably increase or decrease parasite transmission (Ezenwa 2004; Patterson \& Ruckstuhl 2013, Duffy et al. 2019). Given that consumptive interactions likely also have context dependent effects (Duffy et al. 2019), predicting how consumptive and non-consumptive effects differ on average is challenging. However, based on the range of examples of non-consumptive interactions increasing parasitism, we predict that the effects of non-consumptive interactions on parasites should be less consistently negative than those of consumptive interactions.

While multiple syntheses of predator-prey-parasite interactions have been published over the past 20 years (Ostfeld \& Holt 2004; Hatcher et al. 2006; Duffy et al. 2019), these studies take a qualitative approach while here we use an approach that explicitly quantifies the typical effect of predators on parasites in their prey and the most important drivers of variation in this response. Here we ask: (i) what is the average overall effect of predators on parasites in their prey and (ii) does this effect vary by parasite or interaction type? We expect to find a negative overall effect of predation on parasitism, but this effect should be more negative for macroparasites and parasitoids than microparasites and for interactions involving consumptive than non-consumptive interactions. We also expect that consumptive interactions involving identified "predatorspreaders" should have more positive effects than those with non-spreaders.

\section{MATERIALS AND METHODS}

\section{Study Search and Screening}

To identify candidate studies we performed a systematic search of the Web of Science Core Collection using the following search string: predat* AND (parasit* OR pathogen*). This search identified 11,417 candidate studies. Abstracts were subsequently screened to determine if they met three strict inclusion criteria: they must have (i) involved an animal host/prey population, a predator population that kills and consumes the host/prey, and a parasite that is described in the study as infecting the host/prey but NOT the predator; 
(ii) observed multiple levels of predation pressure, and (iii) measured at least one relevant parasite outcome (e.g. intensity or prevalence). Based on abstract screening 256 studies were identified as potentially meeting these three criteria, 50 of which were confirmed following full-text screening (Supplementary Figure 1).

\section{Effect-size and study trait variable extraction}

We recorded the following information from each study to allow direct comparison of effect sizes, test the effect of study features (moderators) on this effect, and control for variation between studies: host/prey taxa to test for a phylogenetic trend in our models; parasite type (macroparasite, microparasite, or parasitoid), study design (observational or experimental), predator interaction type (all or non-consumptive), and predatorspreader identity (predator-spreader or not) for inclusion in mixed effects models (MEMs) testing the effect of these moderators on effect sizes. The majority of studies (45 of 50) were composed of a binary comparison of a parasite response across two levels of predation. Most studies were analyzed using multivariate statistics which makes statistical comparison of effect sizes across studies challenging (Borenstein et al. 2017). For this reason, we extracted the mean parasite response value, sample size, and measure of variation (typically $\mathrm{SE}, \mathrm{SD}$, or $95 \% \mathrm{CI}$ ) from the text or figures of each of these studies and calculated the standardized mean difference (Hedges g) using the escalc function in the R package metafor (Viechtbauer 2010). A small minority of studies ( 5 of 50) reported parasite responses over a range of predation pressures. We converted responses from 3 of these studies to binary effect sizes by using raw data provided to compare the mean parasite response for samples in the first quartile of predator abundance to those in the 4th quartile of predator abundance. We excluded studies from further analysis if sufficient data for this procedure were not provided. Following this protocol we extracted 193 effect sizes from 48 studies (Table 1).

Not all effect sizes contain the same type of information because of differences in the biology of parasites and in the associated response metric. For our study, we grouped effect sizes into 2 broad categories based on the parasite response that was measured: (i) the number or proportion of hosts infected (quantified as prevalence, number or density of infected individuals, or disease induced mortality rate; $n=89$ effect sizes from 22 different studies, Table 2) and (ii) the number of parasites in an average individual (quantified as parasite intensity or parasite load; $n=61$ effect sizes from 19 different studies). Because we expected that predators would have different effects on prevalence and intensity measures (for example a small amount of selective predation on a population with highly aggregated parasites may have a large effect on mean intensity but a small effect on prevalence), we analyzed these responses separately. Another distinction we made was to separate parasites from parasitoids. Parasitoids behave like both predators and parasites over the course of their life-cycle. Adult parasitoids are free-living flies and wasps that lay eggs on live hosts, but the juvenile parasitoids that hatch from these eggs are obligately parasitic and typically lethal to the host. Consequently, the effect of predators on parasitoids in prey may result from different processes than the effects on typical parasites. For this reason, we analyzed parasitoids $(n=43$ effect sizes from 11 different studies) separately from parasites.

\section{Statistical Analysis}

\section{Main Effect and Publication Bias}

We analyzed effect size data for each of the three categories of our data (prevalence, intensity, parasitoid) according to the following scheme. First, we fit a random effects model (REM) to estimate the overall effect of predators on parasites in prey. We report the size and direction of the overall effect as well as $\mathrm{I}^{2}$, a measure of heterogeneity that can be interpreted as the proportion of total variation that is due to between study variation (Higgins \& Thompson 2002). We also used these models to diagnose publication bias in the data by visualizing the relationship between effect size and variance with a funnel plot and testing for a significant correlation between these traits using a rank-order correlation test. If significant correlation was detected, we used the trim-and-fill method (Duval \& Tweedie 2000) to determine whether introduction of studies to balance the diagnosed bias would alter the main effect.

Effects of Moderators 
Given the level of variation in the effect of predators on parasites in prey we were interested in identifying attributes of the study or study system that were most important for explaining variation in effect sizes across studies. To do this, we fit mixed effects models (MEM) to the prevalence and intensity effect size data sets, including a series of moderators: predator effect type manipulated (non-consumptive vs. all interaction types), predator-spreader identity (identified as predator-spreader or not), and parasite type (macro vs. micro) and all two-way interactions. We note that because studies in which the predator was described as a viable host for the parasite were excluded all predator-spreaders are non-host spreaders. Study design (experimental vs. observational) was also included as a moderator to control for variation in responses but without a particular hypothesis. We also included study as a random effect. We note that while we were interested in the distinction between non-consumptive and consumptive effects, most consumptive effect studies technically allowed for both non-consumptive and consumptive interactions due to limitations in experimental design. Therefore we draw the distinction between studies which manipulate only non-consumptive interactions and those which include consumptive interactions (all interaction types). From this model, we generated candidate sets of all possible MEMs for each data set and used the Akaike information criterion corrected for sample size (AICc) to compare model fit. We calculated the importance (on a scale from 0 to 1 ) of each moderator as the summed model weights for all MEMs in which a given moderator occurred. We then fit univariate models for each moderator to identify the direction of the effect. When reporting the results of univariate models for the most important variables, we provided the direction of the effect of the moderator and the results of a test for residual variation. Because parasitoid studies were uniformly terrestrial, experimental, and consumptive, we did not fit MEMs with moderators to these data.

\section{Assessing Phylogenetic Signal}

Because of shared evolutionary history, closely related host species may have similar effect sizes. We use Pagel's lambda (Pagel 1999) to estimate phylogenetic signal in the distribution of effect sizes across taxa. We obtained a phylogeny of relevant prey/host species from the Open Tree of Life using the ROTL package (Hinchliff et al. 2015; Michonneau et al. 2016); then we used the apepackage to prune the tree to our host species, to resolve polytomies, and to generate branch lengths (Paradis \& Schliep 2018). For host species with multiple effect sizes, we calculated the average effect size for each species weighted by the sample size of each component study. We then used the pgls function of thecaper package to estimate Pagel's lambda by maximum likelihood for each of our datasets (Orme et al.2018). We statistically tested the difference between this estimate and two alternative hypotheses: phylogenetic independence (lambda $=0$ ) and phylogenetic dependence as characterized by Brownian motion (lambda =1). We failed to detect evidence of phylogenetic dependence in any dataset using this method.

\section{RESULTS}

\section{Study Patterns}

We identified substantial gaps in the literature reviewed for certain combinations of moderators (Table 2). In particular, no observational studies considered non-consumptive effects, and no studies that measured parasitism by intensity metrics or that studied macroparasites manipulated the effect of predator-spreaders. Both micro- and macroparasites are represented in studies measuring both prevalence and intensity but macroparasites were more common in intensity studies $(n=41 / 61)$ and microparasites more common in prevalence studies $(n=66 / 89)$. Both macro- and microparasites had the effects of both interaction types studied in fairly even proportions, but non-consumptive effects were more represented in macroparasite prevalence studies while they were more common in microparasite intensity studies.

\section{Parasite Prevalence}

A REM of prevalence effect sizes showed an overall effect that was not significantly different from zero ( $\mathrm{z}$ $=1.818, \mathrm{p}=0.069$; Figure 1a), with a large amount of heterogeneity between studies $\left(\mathrm{I}^{2}=91.00 \%\right)$, and significant publication bias $(?=0.200, \mathrm{p}=0.005)$. The trim-and-fill method estimated 18 missing negative studies, but inclusion of these studies did not change the outcome, with the modified REM still showing no evidence of an effect $(\mathrm{z}=-0.795, \mathrm{p}=0.427)$. In our analysis of moderators, predator-spreader identity was 
included in nearly all MEMs with non-zero weights (Importance $=0.993$; Figure 2A, Table 3 ). Interaction type was also important (Importance $=0.771$ ), but other main effects were less so (parasite type importance $=0.620$; study design importance $=0.547$ ). The most important interaction term was between interaction type and predator-spreader identity $($ Importance $=0.665$ ). In univariate analyses, only predator-spreader identity significantly affected mean effect size $\left(\mathrm{QM}_{1}=11.278, \mathrm{p}=0.0008\right)$, despite significant residual heterogeneity $\left(\mathrm{QE}_{87}=630.561, \mathrm{p}<0.001\right)$. Predator-spreaders had more positive effects than non-spreader predators (Figure 3 ).

\section{Parasite Intensity}

An REM of intensity effect sizes did not detect a statistically significant effect of increased predation on parasite intensity in prey $(\mathrm{z}=0.829, \mathrm{p}=0.407$; Figure $1 \mathrm{~b})$, with a large amount of true heterogeneity between studies $\left(\mathrm{I}^{2}=75.93 \%\right)$, and no evidence of publication bias $(?=-0.106, \mathrm{p}=0.231)$. The single most important moderator was interaction type (Importance $=0.775$; Figure $2 \mathrm{~b}$, Table 3 ), and this was the only variable identified as a significant moderator in subsequent univariate analyses $\left(\mathrm{QM}_{1}=5.848, \mathrm{p}=0.016\right)$, despite significant residual heterogeneity $\left(\mathrm{QE}_{59}=182.050, \mathrm{p}<0.001\right)$. Non-consumptive interactions had more positive effects than all interactions (Figure 3).

\section{Parasitoids}

An REM of parasitoid effect sizes detected a statistically significant, negative, overall effect of predation on parasitoid abundance in prey $(\mathrm{z}=-6.919, \mathrm{p}<0.001$; Figure $1 \mathrm{c})$, with a smaller amount of heterogeneity between studies as compared to the analyses of parasite responses $\left(\mathrm{I}^{2}=35.47 \%\right)$. While there was evidence of significant publication bias $(?=-0.227, \mathrm{p}=0.032)$, the inclusion of 9 missing positive effect sizes estimated by the trim and fill method did not eliminate the overall significant negative effect of predators on parasitoids $(\mathrm{z}=-4.630, \mathrm{p}<0.001)$.

\section{DISCUSSION}

The healthy herds hypothesis (HHH) (Packer et al.2003) predicts that predators should have negative effects on parasites in their prey, but empirical studies testing this hypothesis have reported a variety of different effects. We hypothesized that this variation is a result of nuances in predator-prey-parasite interactions, including transmission strategy of the parasite studied and the type of predator interaction manipulated. Specifically, we hypothesized that the negative effect predicted by the $\mathrm{HHH}$ would be larger for macroparasites and parasitoids than for microparasites and would only hold when consumptive interactions are manipulated and when those predators are not "predator-spreaders". Using a meta-analytic approach that accounted for potential sources of variation in observed predator-prey-parasite interaction outcomes, we found that the main effect of predators on parasites in prey differed between parasites and parasitoids but not between conventional macro- and microparasites, with a net negative effect only present for parasitoids. Additionally, we found that interaction type (all vs. non-consumptive), and its subset of predator-spreader interactions, were most important in predicting the effect of predators on parasites in prey. These findings provide clear evidence that the HHH prediction is not universal. The degree to which it holds in a given system is both parasite- and context-dependent, but also predictable with limited information.

We observed significant heterogeneity across studies of the HHH resulting from substantial variation in the magnitude and direction of the main effect of predators on parasites in prey. We, therefore, sought to determine if there were factors that explained this variation in effects. First, we found that the difference between consumptive and non-consumptive interactions can explain variation in the effect of predators on parasites, but specific mechanisms of those interactions are also very important. In studies that measured intensity variables, the effect size significantly differed between interactions involving consumptive and nonconsumptive interactions, with non-consumptive interactions having generally more positive effects. This result aligns with our prediction that consumptive interactions will have more negative effects on parasites compared with non-consumptive interactions. We note that our studies involving consumptive interactions typically were open to all sorts of interactions including non-consumptive, suggesting that this result may, in fact, be conservative. Our result for studies measuring prevalence variables contradicts this finding as 
consumptive and non-consumptive interactions were estimated to be nearly identical on average. We suggest that the difference between these two response variables is an artifact of the significant residual heterogeneity even in our best fit models. Most of this variation is likely hidden in unexplored mechanisms within these studies. Duffyet al. (2019) outlined 7 independent mechanisms whereby consumption can directly or indirectly impact disease in prey. For example, predators can selectively prey on uninfected individuals, shift host population structure toward more susceptible or heavily infected classes, and suppress competition between hosts allowing them to support more parasites. Unfortunately few studies provide sufficient information to assess which mechanisms are at play. Nonetheless, we were able to directly test this idea by including one of these mechanisms (predator-spreaders; (Caceres et al.2009)) as a moderator variable since researchers typically identified this attribute of predators in their studies. As expected, predator-spreader identity was highly important for predicting the parasite outcome in the prevalence dataset, generally increasing parasite prevalence. The difference in the number of predator-spreader effect sizes between prevalence $(n=25)$ and intensity $(n=0)$ responses explains why we saw this effect emerge in the prevalence but not intensity dataset. Ultimately, the lack of universal support for the HHH is a result of the conflicting negative effects in studies of typical consumptive interactions versus positive effects in studies of consumptive predator-spreader interactions and certain non-consumptive interactions,

Second, unlike predator interaction type, we failed to detect an effect of parasite type in our analysis. We hypothesized that differences in the aggregation patterns of micro- and macroparasites would result in macroparasites having a stronger and more negative response to predator pressure than microparasites, but found no evidence for a difference between parasite types in either intensity or prevalence effect sizes and this variable was generally of less importance for explaining variation. This lack of an effect may be due to a number of factors. While one might expect random predation, or predation on infected individuals, to decrease parasitism more when parasites are aggregated (Packer et al.2003), the opposite is also true. Gape limited predators, such as many piscivorous fish and carnivorous snakes (Nilsson \& Bronmark 2000; King 2002) that selectively prey on smaller and younger individuals may cause population demographics to shift towards larger, older and more heavily infected hosts (Dobson 1989; Nilsson \& Bronmark 2000; Byers et al. 2015; Duffy et al. 2019). Alternatively, our assumption that high aggregation among macroparasites makes them more vulnerable to predation may be countered by the existence of significant aggregation in microparasite systems as well (Lord et al. 1999; Grogan et al. 2016).

Third, while there may not be a significant difference between micro- and macroparasites we saw a clear difference between parasites and parasitoids. Even when controlling for publication bias, predators had a significant negative effect on parasitoids as compared to the lack of any overall effect on parasites. Our ability to detect a strong directional effect for parasitoids is perhaps partly due to the uniformity across the studies in the parasitoid analysis, also supported by the more limited heterogeneity in the parasitoid REM. The negative direction of the effect may be due to the fact that consumptive effects of predators on parasitoids rarely include mechanisms that could produce positive effects. Predators rarely act in a "spreader" role for parasitoids in their prey because the larval life-cycle of the parasitoid is typically interrupted by predation (Naselli et al.2017). Perhaps most non-consumptive effects of predators on parasitoids concern free-living adult life stages, which may avoid areas with predators due to direct intraguild predation of predators on adult parasitoids (Heimpelet al. 1997; Brodeur \& Rosenheim 2000). As a result, it is conceivable that parasitoids would display the a stronger negative response to predator addition than other parasitic organisms.

One of the main limitations of this study, as with all quantitative synthesis, is the selection bias in the field being synthesized. We detected significant publication bias in the literature in multiple directions. Particularly, our analysis of prevalence showed a significant bias towards publication of positive effect sizes, probably due to the abundance of predator-spreader associated effect sizes. In the case of parasitoids, however, there was significant evidence of publication bias for negative effect sizes. While correction for these biases did not influence qualitative conclusions, their presence does suggest the need for additional attention to the types of results published. Besides publication bias in effect sizes, we noted a number of important imbalances in study characteristics, particularly the lack of observational studies that inspected non-consumptive effects. We also found that studies which identified predators as predator-spreaders were 
largely limited to studies of microparasite prevalence. This finding suggests that the empirical dissection of consumptive effect mechanisms is not only limited to cases that are easy to characterize (like predatorspreaders), but also limited in taxonomic coverage. Given these gaps in the literature, we suggest the following priorities for future work: (i) examining the effect of non-consumptive predator interactions on parasites in non-manipulative field observations and (ii) further dissecting the effect of predator-spreaders and other types of consumptive interactions on both micro- and macroparasites.

Overall, we found that the healthy herds hypothesis is not broadly supported by the current literature. Instead, the average effect of predators on parasites in prey varies significantly according to the type of interaction being studied and whether the focus is on parasites or parasitoids. Our findings provide the first quantitative analysis supporting the growing consensus (Hethcote et al. 2004; Choisy \& Rohani 2006; Holt \& Roy 2007; Roy \& Holt 2008; Duffy et al.2019) that predator effects on parasites are context dependent. Our results further suggest that the mechanistic basis of predator-prey interactions strongly influences parasite outcomes and that these effects are predictable.

\section{Acknowledgements}

This work was supported by a National Science Foundation Graduate Research Fellowship awarded to RLR. We thank Craig Osenberg and Amy Briggs for helpful conversations and insights into the meta-analysis and Mike Conner and Andrew Park for thoughtful comments on the manuscript.
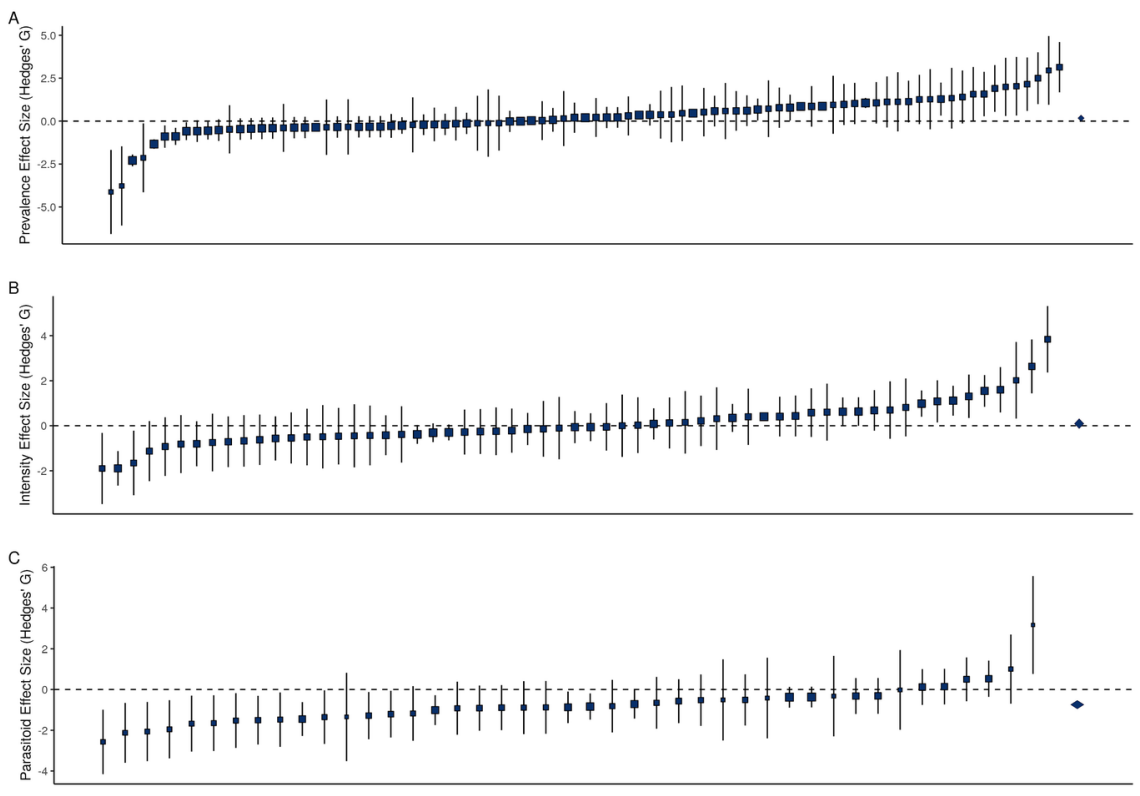

Figure 1. Range and grand means from random-effects meta-analysis models (REMs) for the effect of predators on parasites in prey stratified by prevalence (a) intensity (b) and parasitoid (c) data. Lines show 95\% confidence intervals for effect sizes and REMs (uncorrected for publication bias). The dashed line represents no relationship between condition and infection. 


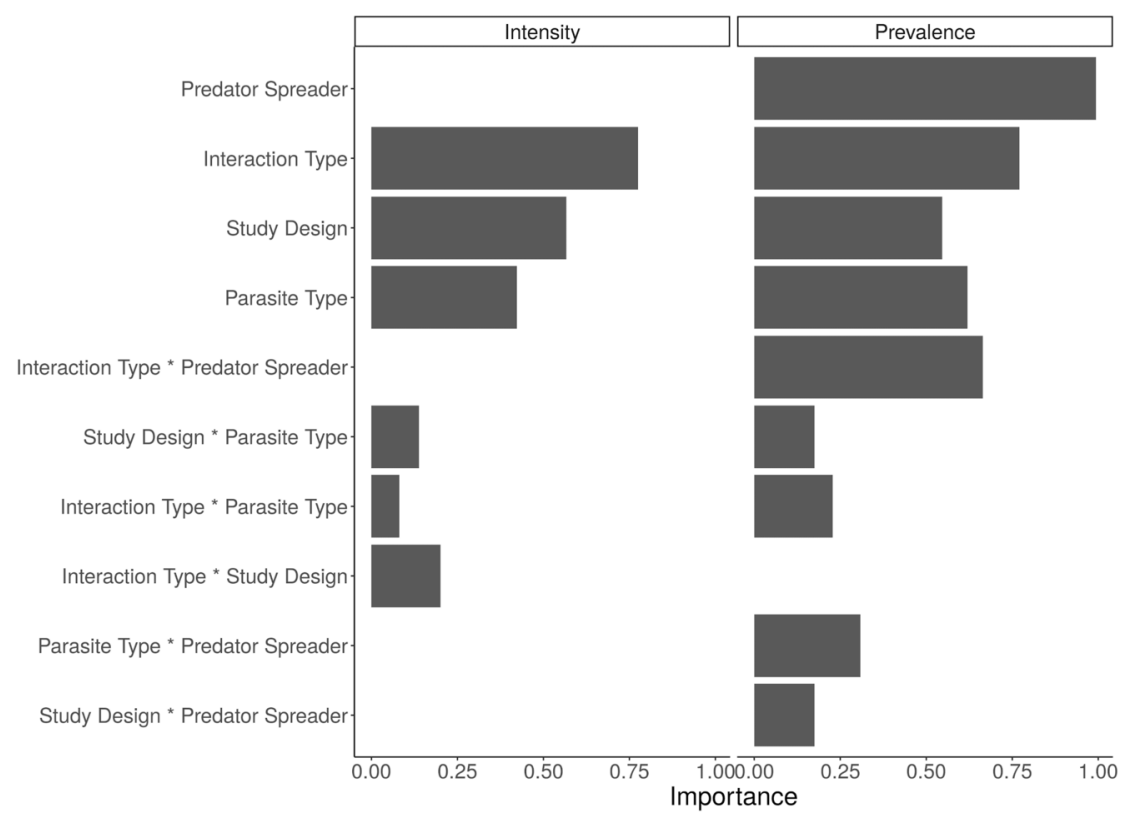

Figure 2. AICc weight based importance of moderators for MEMs of intensity and prevalence effect sizes.

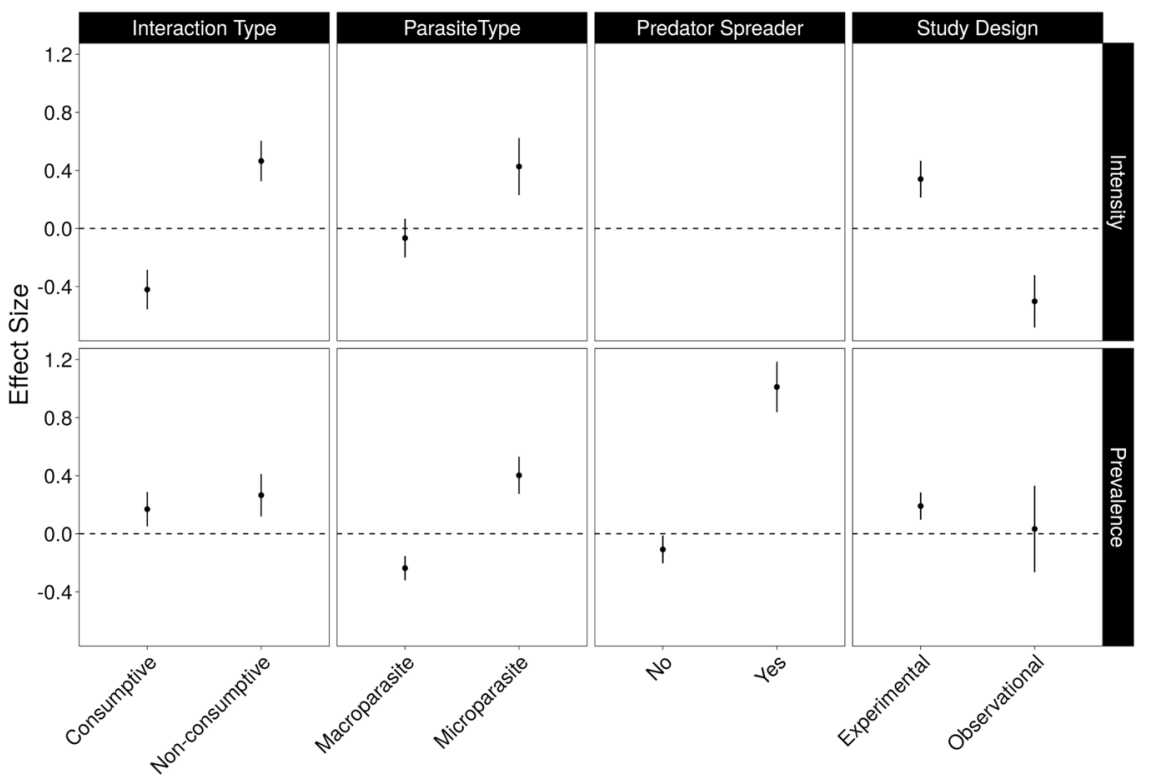

Figure 3. Modeled univariate relationships (means and 95\% confidence intervals) for the four most important moderators of effect size across all intensity data (top row), and prevalence data (bottom row). Results from mixed-effects models are sorted by study traits. Interaction type: consumptive or non-consumptive. Parasite type: macroparasite or microparasite. Predator-spreader identity: identified as a predator-spreader or not. The dashed line represents no relationship between condition and infection.

\section{REFERENCES}


Agboton, B. V., Hanna, R., Onzo, A., Vidal, S., \& von Tiedemann, A. (2013). Interactions between the predatory mite Typhlodromalus aripo and the entomopathogenic fungus Neozygites tanajoae and consequences for the suppression of their shared prey/host Mononychellus tanajoa.Experimental and Applied Acarology , 60, 205-217.

Barber-Meyer, S. M., White, P. J., \& Mech, L. D. (2007). Survey of selected pathogens and blood parameters of northern Yellowstone elk: wolf sanitation effect implications. The American Midland Naturalist , 158, 369-381.

Baverstock, J., Clark, S. J., Alderson, P. G., \& Pell, J. K. (2009). Intraguild interactions between the entomopathogenic fungus Pandora neoaphidis and an aphid predator and parasitoid at the population scale. Journal of invertebrate pathology, 102, 167-172.

Bertram, C. R., Pinkowski, M., Hall, S. R., Duffy, M. A., \& Cáceres, C. E. (2013). Trait-mediated indirect effects, predators, and disease: test of a size-based model. Oecologia , 173, 1023-1032.

Borenstein, M., Higgins, J.P., Hedges, L.V. \& Rothstein, H.R. (2017). Basics of meta-analysis: I2 is not an absolute measure of heterogeneity.Res. Synth. Methods, 8, 5-18.

Borer, E.T., Briggs, C.J. \& Holt, R.D. (2007). Predators, parasitoids, and pathogens: a cross-cutting examination of intraguild predation theory.Ecology, 88, 2681-2688.

Brodeur, J. \& Rosenheim, J.A. (2000). Intraguild interactions in aphid parasitoids.Entomol. Exp. Appl., 97, 93-108.

Brown, J.S., Kotler, B.P., Smith, R.J. \& Wirtz, W.O. (1988). The effects of owl predation on the foraging behavior of heteromyid rodents. Oecologia, 76, 408-415.

Buss, N., \& Hua, J. (2018). Parasite susceptibility in an amphibian host is modified by salinization and predators. Environmental Pollution, 236, 754-763.

Byers, J.E., Malek, A.J., Quevillon, L.E., Altman, I. \& Keogh, C.L. (2015). Opposing selective pressures decouple pattern and process of parasitic infection over small spatial scale. Oikos, 124, 1511-1519.

Cáceres, C.E., Knight, C.J. \& Hall, S.R. (2009). Predator-spreaders: predation can enhance parasite success in a planktonic host-parasite system. Ecology, 90, 2850-2858.

Chacón, J. M., Landis, D. A., \& Heimpel, G. E. (2008). Potential for biotic interference of a classical biological control agent of the soybean aphid. Biological Control , 46, 216-225.

Chailleux, A., Wajnberg, E., Zhou, Y., Amiens-Desneux, E., \& Desneux, N. (2014). New parasitoid-predator associations: female parasitoids do not avoid competition with generalist predators when sharing invasive prey. Naturwissenschaften, 101, 1075-1083.

Chailleux, A., Droui, A., Bearez, P., \& Desneux, N. (2017). Survival of a specialist natural enemy experiencing resource competition with an omnivorous predator when sharing the invasive prey Tuta absoluta.Ecology and evolution , 7, 8329-8337.

Chesson, P. \& Murdoch, W. (1986). Aggregation of Risk - Relationships Among Host-Parasitoid Models. Am. Nat., 127, 696-715.

Choisy, M. \& Rohani, P. (2006). Harvesting can increase severity of wildlife disease epidemics. Proc. R. Soc. B Biol. Sci., 273, 2025-2034.

Colfer, R. G., \& Rosenheim, J. A. (2001). Predation on immature parasitoids and its impact on aphid suppression. Oecologia , 126, 292-304.

Coors, A., \& De Meester, L. (2008). Synergistic, antagonistic and additive effects of multiple stressors: predation threat, parasitism and pesticide exposure in Daphnia magna. Journal of Applied Ecology , 45, $1820-1828$. 
Creel, S., Schuette, P. \& Christianson, D. (2014). Effects of predation risk on group size, vigilance, and foraging behavior in an African ungulate community.Behav. Ecol., 25, 773-784.

Dobson, A.P. (1989). The population biology of parasitic helminths in animal populations. In:Applied mathematical ecology. Springer, pp. 145-175.

Duffy, M.A., Caceres, C.E. \& Hall, S.R. (2019). Healthy herds or predator spreaders? Insights from the plankton into how predators suppress and spread disease. Wildl. Dis. Ecol. Link. Theory Data Appl., 458.

Duval, S. \& Tweedie, R. (2000). A nonparametric "trim and fill" method of accounting for publication bias in meta-analysis. J. Am. Stat. Assoc., 95, 89-98.

Ekesi, S., Shah, P. A., Clark, S. J., \& Pell, J. K. (2005). Conservation biological control with the fungal pathogen Pandora neoaphidis: implications of aphid species, host plant and predator foraging. Agricultural and Forest Entomology , 7, 21-30.

Ezenwa, V.O. (2004). Host social behavior and parasitic infection: a multifactorial approach.Behav. Ecol., $15,446-454$.

Ezenwa, V.O. \& Jolles, A.E. (2011). From host immunity to pathogen invasion: the effects of helminth coinfection on the dynamics of microparasites. Oxford University Press.

Ferguson, K. I., \& Stiling, P. (1996). Non-additive effects of multiple natural enemies on aphid populations. Oecologia , 108, 375-379.

Goertz, D. R., \& Hoch, G. (2013). Effects of the ant F ormica fusca on the transmission of microsporidia infecting gypsy moth larvae.Entomologia experimentalis et applicata , 147, 251-261.

Groner, M. L., \& Relyea, R. A. (2015). Predators reduce B atrachochytrium dendrobatidis infection loads in their prey.Freshwater Biology , 60, 1699-1704.

Haislip, N. A., Hoverman, J. T., Miller, D. L., \& Gray, M. J. (2012). Natural stressors and disease risk: does the threat of predation increase amphibian susceptibility to ranavirus?. Canadian Journal of Zoology, 90, 893-902.

Halstead, N. T., Hoover, C. M., Arakala, A., Civitello, D. J., De Leo, G. A., Gambhir, M., .. \& Rohr, J. R. (2018). Agrochemicals increase risk of human schistosomiasis by supporting higher densities of intermediate hosts. Nature communications, 9, 1-10.

Harvey, C. T., \& Eubanks, M. D. (2005). Intraguild predation of parasitoids by Solenopsis invicta: a nondisruptive interaction.Entomologia Experimentalis et Applicata , 114, 127-135.

Hassell, M.P. (1982). Patterns of parasitism by insect parasitoids in patchy environments.Ecol. Entomol., $7,365-377$.

Hatcher, M.J., Dick, J.T.A. \& Dunn, A.M. (2006). How parasites affect interactions between competitors and predators. Ecol. Lett., 9, 1253-1271.

Hawlena, D., Abramsky, Z. \& Bouskila, A. (2010). Bird predation alters infestation of desert lizards by parasitic mites. Oikos, 119, 730-736.

Heimpel, G.E., Rosenheim, J.A. \& Mangel, M. (1997). Predation on adult Aphytis parasitoids in the field. Oecologia, 110, 346-352.

Hethcote, H.W., Wang, W., Han, L. \& Ma, Z. (2004). A predator-prey model with infected prey.Theor. Popul. Biol., 66, 259-268.

Higgins, J.P. \& Thompson, S.G. (2002). Quantifying heterogeneity in a meta-analysis.Stat. Med., 21, 15391558 . 
Hinchliff, C.E., Smith, S.A., Allman, J.F., Burleigh, J.G., Chaudhary, R., Coghill, L.M.,et al. (2015). Synthesis of phylogeny and taxonomy into a comprehensive tree of life. Proc. Natl. Acad. Sci., 112, 12764-12769.

Hofmeester, T. R., Jansen, P. A., Wijnen, H. J., Coipan, E. C., Fonville, M., Prins, H. H., et al. (2017). Cascading effects of predator activity on tick-borne disease risk. Proceedings of the Royal Society B: Biological Sciences , 284, 20170453.

Holt, R. \& Lawton, J. (1994). The Ecological Consequences of Shared Natural Enemies.Annu. Rev. Ecol. Syst., 25, 495-520.

Holt, R.D. \& Polis, G.A. (1997). A theoretical framework for intraguild predation. Am. Nat., 149, 745-764.

Holt, R.D. \& Roy, M. (2007). Predation can increase the prevalence of infectious disease.Am. Nat., 169, 690-699.

Hudson, P.J., Dobson, A.P. \& Newborn, D. (1992a). Do parasites make prey vulnerable to predation? Red grouse and parasites. J. Anim. Ecol., 681-692.

Hudson, P.J., Newborn, D. \& Dobson, A.P. (1992b). Regulation and stability of a free-living host-parasite system: Trichostrongylus tenuis in red grouse. I. Monitoring and parasite reduction experiments. J. Anim. Ecol., 477-486.

Jansen, M., De Meester, L., Cielen, A., Buser, C. C., \& Stoks, R. (2011). The interplay of past and current stress exposure on the water flea Daphnia. Functional Ecology, 25, 974-982.

Jolles, A.E., Ezenwa, V.O., Etienne, R.S., Turner, W.C. \& Olff, H. (2008). Interactions between macroparasites and microparasites drive infection patterns in free-ranging African buffalo. Ecology, 89, 2239-2250.

Jones, E.I. \& Dornhaus, A. (2011). Predation risk makes bees reject rewarding flowers and reduce foraging activity. Behav. Ecol. Sociobiol., 65, 1505-1511.

Kaneko, S. (2007). Predator and parasitoid attacking ant-attended aphids: effects of predator presence and attending ant species on emerging parasitoid numbers. Ecological Research , 22, 451-458.

King, R.B. (2002). Predicted and observed maximum prey size - snake size allometry.Funct. Ecol., 16, $766-772$.

Koprivnikar, J., \& Urichuk, T. M. (2017). Time-lagged effect of predators on tadpole behaviour and parasite infection. Biology letters , 13, 20170440.

Krebs, C.J., Boonstra, R., Kenney, A.J. \& Gilbert, B.S. (2018). Hares and small rodent cycles: a 45-year perspective on predator-prey dynamics in the Yukon boreal forest. Aust. Zool., 39, 724-732.

Krebs, C.J., Boutin, S., Boonstra, R., Sinclair, A.R.E., Smith, J.N.M., Dale, M.R.T.,et al. (1995). Impact of Food and Predation on the Snowshoe Hare Cycle. Science, 269, 1112-1115.

Kuris, A.M. (2003). Evolutionary ecology of trophically transmitted parasites. J. Parasitol., 89, S96-S100.

Lafferty, K.D. (1999). The evolution of trophic transmission. Parasitol. Today, 15, 111-115.

Laws, A. N., Frauendorf, T. C., Gomez, J. E., \& Algaze, I. M. (2009). Predators mediate the effects of a fungal pathogen on prey: an experiment with grasshoppers, wolf spiders, and fungal pathogens.Ecological Entomology , 34, 702-708.

Logiudice, K. (2003). Trophically transmitted parasites and the conservation of small populations: raccoon roundworm and the imperiled Allegheny woodrat.Conserv. Biol., 17, 258-266.

Malek, J. C., \& Byers, J. E. (2016). Predator effects on host-parasite interactions in the eastern oyster Crassostrea virginica. Marine Ecology Progress Series , 556, 131-141. 
Marino Jr, J. A., \& Werner, E. E. (2013). Synergistic effects of predators and trematode parasites on larval green frog (Rana clamitans) survival. Ecology, 94, 2697-2708.

Marino Jr, J. A., Holland, M. P., \& Werner, E. E. (2016). Competition and host size mediate larval anuran interactions with trematode parasites. Freshwater Biology, 61, 621-632.

Martin, C. H., \& Johnsen, S. (2007). A field test of the Hamilton-Zuk hypothesis in the Trinidadian guppy (Poecilia reticulata).Behavioral Ecology and Sociobiology , 61, 1897-1909.

Memmott, J., Godfray, H. C. J., \& Bolton, B. (1993). Predation and parasitism in a tropical herbivore community. Depredacion y parasitismo en una comunidad herbivora tropical. Ecological Entomology. , 18, 348-352.

Michonneau, F., Brown, J.W. \& Winter, D.J. (2016). rotl: an R package to interact with the Open Tree of Life data. Methods Ecol. Evol., 7, 1476-1481.

Mohammed, A. A. (2018). Lecanicillium muscarium and Adalia bipunctata combination for the control of black bean aphid, Aphis fabae.BioControl , 63, 277-287.

Moore, J. (2002).Parasites and the behavior of animals. Oxford University Press on Demand.

Naselli, M., Biondi, A., Tropea Garzia, G., Desneux, N., Russo, A., Siscaro, G., et al. (2017). Insights into food webs associated with the South American tomato pinworm. Pest Manag. Sci., 73, 1352-1357.

Nilsson, P.A. \& Bronmark, C. (2000). Prey vulnerability to a gape-size limited predator: behavioural and morphological impacts on northern pike piscivory. Oikos, 88, 539-546.

O'Connor, J. A., Dudaniec, R. Y., \& Kleindorfer, S. (2010). Parasite infestation and predation in Darwin's small ground finch: contrasting two elevational habitats between islands. Journal of Tropical Ecology , 285-292.

Orlofske, S. A., Jadin, R. C., Hoverman, J. T., \& Johnson, P. T. (2014). Predation and disease: understanding the effects of predators at several trophic levels on pathogen transmission. Freshwater Biology, 59, 1064-1075.

Orme, D., Freckleton, R., Thomas, G., Petzoldt, T., Fritz, S., Isaac, N., et al.(2018). caper: Comparative Analyses of Phylogenetics and Evolution in R.

Ostfeld, R.S. \& Holt, R.D. (2004). Are predators good for your health? Evaluating evidence for top-down regulation of zoonotic disease reservoirs. Front. Ecol. Environ., 2, 13-20.

Packer, C., Holt, R.D., Hudson, P.J., Lafferty, K.D. \& Dobson, A.P. (2003). Keeping the herds healthy and alert: implications of predator control for infectious disease. Ecol. Lett., 6, 797-802.

Pagel, M. (1999). Inferring the historical patterns of biological evolution.Nature, 401, 877-884.

Paradis, E. \& Schliep, K. (2018). ape 5.0: an environment for modern phylogenetics and evolutionary analyses in R. Bioinformatics, 35, 526-528.

Patterson, J.E. \& Ruckstuhl, K.E. (2013). Parasite infection and host group size: a meta-analytical review. Parasitology, 140, 803-813.

Peacock, S. J., Krkošek, M., Bateman, A. W., \& Lewis, M. A. (2015). Parasitism and food web dynamics of juvenile Pacific salmon.Ecosphere, 6, 1-16.

Pedersen, A.B. \& Fenton, A. (2007). Emphasizing the ecology in parasite community ecology. Trends Ecol. Evol., 22, 133-139.

Penczykowski, R. M., Hall, S. R., Civitello, D. J., \& Duffy, M. A. (2014). Habitat structure and ecological drivers of disease.Limnology and Oceanography, 59, 340-348. 
Pérez-Jvostov, F., Hendry, A. P., Fussmann, G. F., \& Scott, M. E. (2012). Are host-parasite interactions influenced by adaptation to predators? A test with guppies and Gyrodactylus in experimental stream channels. Oecologia , 170, 77-88.

Raffel, T. R., Hoverman, J. T., Halstead, N. T., Michel, P. J., \& Rohr, J. R. (2010). Parasitism in a community context: trait-mediated interactions with competition and predation. Ecology , 91, 1900-1907.

Ramirez-Ahuja, M. d. L., Rodriguez-Leyva, E., Lomeli-Flores, J. R., Torres-Ruiz, A., \& Guzman-Franco, A. W. (2017). Evaluating combined use of a parasitoid and a zoophytophagous bug for biological control of the potato psyllid, Bactericera cockerelli. Biological Control , 106, 9-15.

Reeve, B. C., Crespi, E. J., Whipps, C. M., \& Brunner, J. L. (2013). Natural stressors and ranavirus susceptibility in larval wood frogs (Rana sylvatica). EcoHealth , 10, 190-200.

Roux, O., Vantaux, A., Roche, B., Yameogo, K. B., Dabire, K. R., Diabate, A., et al. (2015). Evidence for carry-over effects of predator exposure on pathogen transmission potential. Proceedings of the Royal Society B: Biological Sciences , 282, 20152430.

Roy, H. E., Pell, J. K., Clark, S. J., \& Alderson, P. G. (1998). Implications of predator foraging on aphid pathogen dynamics. Journal of Invertebrate Pathology , 71, 236-247.

Roy, M. \& Holt, R.D. (2008). Effects of predation on host-pathogen dynamics in SIR models. Theor. Popul. Biol., 73, 319-331.

Shaw, D.J. \& Dobson, A.P. (1995). Patterns of macroparasite abundance and aggregation in wildlife populations: a quantitative review. Parasitology, 111, S111-S133.

Sokolow, S. H., Huttinger, E., Jouanard, N., Hsieh, M. H., Lafferty, K. D., Kuris, A. M., et al. (2015). Reduced transmission of human schistosomiasis after restoration of a native river prawn that preys on the snail intermediate host. Proceedings of the National Academy of Sciences, 112, 9650-9655.

Spieler, M. (2003). Risk of predation affects aggregation size: a study with tadpoles of Phrynomantis microps (Anura: Microhylidae). Anim. Behav., 65, 179-184.

Stephenson, J. F., Van Oosterhout, C., Mohammed, R. S., \& Cable, J. (2015). Parasites of Trinidadian guppies: evidence for sex-and age-specific trait-mediated indirect effects of predators.Ecology , 96, 489-498.

Strauss, A.T., Shocket, M.S., Civitello, D.J., Hite, J.L., Penczykowski, R.M., Duffy, M.A., et al. (2016). Habitat, predators, and hosts regulate disease in Daphnia through direct and indirect pathways. Ecol. Monogr., 86, 393-411.

Szuroczki, D. \& Richardson, J.M. (2012). The behavioral response of larval amphibians (Ranidae) to threats from predators and parasites. PLoS One, 7, e49592.

Szuroczki, D., \& Richardson, J. M. (2018). Correction: The Behavioral Response of Larval Amphibians (Ranidae) to Threats from Predators and Parasites. PloS one, 13, e0203252.

Tallian, A., Ordiz, A., Metz, M.C., Milleret, C., Wikenros, C., Smith, D.W., et al.(2017). Competition between apex predators? Brown bears decrease wolf kill rate on two continents. Proc. R. Soc. B Biol. Sci., $284,20162368$.

Tan, X., Hu, N., Zhang, F., Ramirez-Romero, R., Desneux, N., Wang, S., \& Ge, F. (2016). Mixed release of two parasitoids and a polyphagous ladybird as a potential strategy to control the tobacco whitefly Bemisia tabaci. Scientific Reports , 6, 1-9.

Thiemann, G. W., \& Wassersug, R. J. (2000). Patterns and consequences of behavioural responses to predators and parasites in Rana tadpoles.Biological Journal of the Linnean Society , 71, 513-528.

Tompkins, D.M. \& Begon, M. (1999). Parasites can regulate wildlife populations.Parasitol. Today, 15, $311-313$. 
Trandem, N., Berdinesen, R., Pell, J. K., \& Klingen, I. (2016). Interactions between natural enemies: Effect of a predatory mite on transmission of the fungus Neozygites floridana in two-spotted spider mite populations. Journal of invertebrate pathology , 134, 35-37.

Viechtbauer, W. (2010). Conducting meta-analyses in R with the metafor package. J. Stat. Softw., 36, 1-48.

Yin, M., Laforsch, C., Lohr, J. N., \& Wolinska, J. (2011). Predator-induced defense makes Daphnia more vulnerable to parasites.Evolution: International Journal of Organic Evolution, 65, 1482-1488.

\section{Hosted file}

Table 1.docx available at https://authorea.com/users/423257/articles/528766-do-predatorskeep-prey-healthy-or-make-them-sicker-a-meta-analysis

\section{Hosted file}

Table 2.xlsx available at https://authorea.com/users/423257/articles/528766-do-predatorskeep-prey-healthy-or-make-them-sicker-a-meta-analysis

\section{Hosted file}

Table 3.xlsx available at https://authorea.com/users/423257/articles/528766-do-predatorskeep-prey-healthy-or-make-them-sicker-a-meta-analysis 